\section{CPS-399 EVALUATING CLINICAL PHARMACY SERVICES ON AN INTENSIVE CARE UNIT: A SATISFACTION SURVEY}

M Valera Rubio*, N Martinez Casanova, MC Sanchez Argaiz, I Moya Carmona. Hospital Virgen De La Victoria, Hospital Pharmacy, Málaga, Spain

\subsection{6/ejhpharm-2021-eahpconf.231}

Background and importance Clinical pharmacists involved in critical care are well described in the literature. Additionally, a computerised physician order entry (CPOE) system reduces the incidence of medication errors, especially when it allows pharmacy validation. Despite these potential benefits, integrating new members and implementing new tools in an ICU team is a complex process and it can influence overall staff satisfaction.

Aim and objectives To assess the satisfaction of ICU doctors and nurses with the new critical care pharmacist role during the last 2 years and the new CPOE 1 year after implementation.

Material and methods A cross sectional study was carried out in September 2020 in an 18 bed medical/surgical adult ICU in a second level hospital. A 5 point Likert scale based survey $(5=$ highest level of agreement) was electronically distributed to ICU staff. The surveys contained 17 Likert questions in three sections: pharmacist integration on ICU team; pharmacist role; and CPOE. The results were expressed as a percentage of the maximum score (a value $\geq 4$ ). Demographic data and sections for comments were included. Cronbach's alpha coefficient was performed to assess reliability. Data analysis was conducted using the SPSS statistical software 20.0.

Results $31 / 72$ nurses and 15/18 doctors completed the survey (42\% vs $83.3 \%$ response rate). Regarding the pharmacist's integration, $100 \%$ of doctors versus $22.6 \%$ of nurses knew the pharmacist by name and $100 \%$ of doctors versus $71 \%$ of nurses considered pharmacists accessible professionals. Both considered the pharmacist as an important liaison between the pharmacy and ICU (100\% vs 96.8\%). Doctors were satisfied with statements such as timely resolution to drug related questions (100\% vs $67.7 \%$ of nurses), ICU-pharmacy relationship has improved since the pharmacist joined $(100 \%$ vs $61.3 \%)$ and overall satisfaction with the pharmacist $(100 \%$ vs $64.5 \%)$.

Concerning CPOE: pharmaceutical validation makes the CPOE safer ( $80 \%$ vs $41.9 \%)$, taking into account the pharmacist's advice (90\% vs 96.7\%), and CPOE presents more advantages than disadvantages $(80 \%$ vs $61.3 \%)$. Cronbach's alpha statistical analysis indicated that the survey's reliability was high (nurses 0.77, doctors 0.89).

Conclusion and relevance Physicians appreciated the clinical pharmacist's work and its impact on daily clinical practice. Nurses gave lower scores, but nevertheless their role as an intermediary was highly valued. The evaluation of the new CPOE was satisfactory, however it is necessary to focus on nurses' needs to improve the pharmacist service.

\section{REFERENCES AND/OR ACKNOWLEDGEMENTS}

Conflict of interest No conflict of interest

\section{CPS-400 THE ROLE AND VALUE OF A WARD BASED PHARMACIST IN THE INTENSIVE CARE UNIT: THE CRITICAL CARE PHYSICIANS' AND NURSES' PERCEPTIONS}

DL Rayner*, L Grech, A Serracino Inglott. University of Malta, Department of PharmacyFaculty of Medicine and Surgery, Msida, Malta

10.1136/ejhpharm-2021-eahpconf.232

Background and importance Patients hospitalised within the intensive care unit (ICU) are prescribed almost twice as many medications compared with patients hospitalised within other areas of the hospital. This increases the likelihood of possible drug interactions as well as medication errors. ${ }^{1}$

Aim and objectives The aim of this study was to assess the expected role and perceived value of a ward based pharmacist in the ICU, as deemed by critical care physicians and nurses at an acute general teaching hospital prior to the introduction of the service.

Material and methods The pre-service questionnaires developed by Portelli (2018), targeting nurses and physicians, respectively, were adapted to portray the requirements of a critical care setting and validated for content by an expert panel. The validated tools were disseminated among ICU based physicians and nurses. The responses obtained were analysed descriptively and by content analysis.

Results The vast majority of nurses gave a score of 4 or higher on a 5 point Likert scale (with $5=$ essential) when asked whether they felt there was a need for an inhouse pharmacist in the ICU. Similarly, the majority of physicians gave a score of 4 or higher on the same 5 point Likert scale when posed the same question.

Conclusion and relevance The delivery of direct, proactive, patient centred care by pharmacists has been correlated with both actual and perceived improvement in patient outcomes. ${ }^{2}$

3 Most of the respondents were positive that the presence of a pharmacist in the ICU would improve the outcomes for patient safety and better quality care.

\section{REFERENCES AND/OR ACKNOWLEDGEMENTS}

1. Richter $A$, Bates I, Thacker $M$, et al. Impact of the introduction of a specialist critical care pharmacist on the level of pharmaceutical care provided to the critical care unit. Int J Pharm Pract 2016;24:253-61.

2. Preslaski CR, Lat I, MacLaren $\mathrm{R}$, et al. Pharmacist contributions as members of the multidisciplinary ICU team. Chest 2013;144:1687-95.

3. Mailman JF, Semchuk W. Pharmacists' roles in critical care: Environmental scan of current practices in Canadian intensive care units. Can J Hosp Pharm 2018;71:215-16.

Conflict of interest No conflict of interest

\section{CPS-401 TELEPHARMACY PROGRAMME IMPLEMENTATION DURING THE COVID-19 PANDEMIC}

${ }^{1} \mathrm{~A}$ Martínez*, ${ }^{2} \mathrm{~A}$ Mesa Jimenez, ${ }^{2} \mathrm{~L}$ Rendon De Lope, ${ }^{2} \mathrm{R}$ Castillejo Garcia, ${ }^{2} \mathrm{C}$ Castillo Martin, ${ }^{2} \mathrm{U}$ Baños Roldan. ${ }^{1}$ Clinical Pharmacist, Hospital Pharmacy, Sevilla, Spain; ${ }^{2}$ Hospital Universitario Virgen Macarena, Hospital Pharmacy, Sevilla, Spain

10.1136/ejhpharm-2021-eahpconf.233

Background and importance The COVID-19 pandemic has created a new scenario for the dispensing of hospital drugs. 